\title{
A modalidade escrita do português como L2 para alunos surdos: análise de abordagem em classe de inclusão no ensino médio
}

\author{
José de Sousa Silva (SOUSA SILVA, José de) \\ Mestre pela Universidade de Brasília, Intérprete de Libras GDF \\ jssilva@unb.br \\ José Carlos Almeida Filho (ALMEIDA FILHO, José Carlos P.) \\ Professor Doutor da Universidade de Brasília - UnB \\ jcpaes@unb.br
}

\section{Resumo}

Neste artigo buscamos analisar a abordagem de ensinar Língua Portuguesa em modalidade escrita numa classe inclusiva composta de alunos com surdez profunda e alunos ouvintes a partir da filmagem de uma aula de produção de texto com o intuito de interpretar evidências de adequação do insumo oferecido e co-construído em sala e de permeabilidade do filtro sócio-afetivo. Registrou-se uma abordagem formal textualista pouco voltada para a verdadeira inserção do surdo na escola regular dos ouvintes.

Palavras-chave: Segunda língua, L2, insumo, filtro sócio-afetivo, abordagem, LIBRAS, análise de abordagem.

\begin{abstract}
The aim of this research study was to analyze the language teaching approach underlying a regular Portuguese Language class meant as an inclusion context for deep deaf students. The task was made possible by videotaping a text production class to check for the appropriateness/ inappropriateness of input and for the permeability of the socio-affective filter. It was observed that a formal textualist approach was in place and that it was insufficiently concerned with the deaf learner to be a truly inclusive instrument.
\end{abstract}

Keywords: Second language, L2, input, socio-affective filter, approach, LIBRAS (Brazilian Sign Language), approach analysis. 


\section{Introdução}

Este trabalho de pesquisa aplicada no âmbito da linguagem, especificamente na subárea de Ensino-Aprendizagem de Línguas, documentou e analisou fatos contextualizados de uma sala de aula inclusiva que julgamos capazes de caracterizar a abordagem ou filosofia orientadora do processo de ensino-aprendizagem observado no desempenho em sala de uma professora de Língua Portuguesa (LP). Nesse contexto, a professora analisada busca criar condições para a produção de um texto na classe de inclusão ${ }^{1}$ com alunos surdos profundos e ouvintes de um segundo ano do ensino médio.

A acepção do termo abordagem considerada neste trabalho é aquela proposta em Almeida Filho (1993, 1999, 2007) como um saber revelado num saber fazer (largamente não-consciente na vida do professor), mas que desejavelmente deve crescer em consciência à medida que cresce o saber teórico, marcado por certas atitudes, sobre o exercício docente do ensino de línguas e a aprendizagem que se empreende em cada contexto. Abordagem, tomada como esse saber fazer espontâneo em larga medida, equivale ao sentido do termo habitus de Bourdieu (1991) para se referir ao conhecimento intuitivo do professor que advém de suas experiências particulares no exercício da profissão e que se acumulam como expectativas de um fazer naturalizado.

Ao engajarmos o conceito de abordagem como uma filosofia de ensinar (língua e Português escrito como L2 no nosso caso), é necessário estabelecer algumas precauções. No campo de ensino de segunda língua e/ou língua estrangeira para alunos ouvintes se destacam, de forma geral, duas abordagens: a gramatical ou estruturalista, focada na precedência da gramática e seu manejo como base para se instaurar uma competência de uso da nova língua e a comunicacional focada no ensino e aquisição da nova língua a partir de experiências significativas de uso da língua-alvo em interação real (em oposição a simulacros de uso com desempenho de papéis em discurso préfabricado).

No campo específico da educação de alunos surdos as "abordagens" principais até aqui têm sido: (i) a oralista (desde o século XVIII) com foco na reabilitação do surdo através do ensino da leitura labial e articulação de palavras; (ii) a gestualista (também a partir do século XVIII) que reconhece a existência de uma linguagem própria dos surdos que, mesmo diferente da oral, permite a comunicação, o acesso à cultura e mesmo à língua oral e escrita; (iii) a da comunicação total (séc. XX) que faz uso dos sinais da leitura labial e da fonética articulatória como meio de se ensinar surdos; e hodiernamente, e ainda em desenvolvimento, (iv) a bilingüista que propõe o ensino da língua escrita e/ou oral ao aluno surdo através da língua de sinais desse aluno.

Consideramos que a opção pelo bilingüismo é desejável desde que o aluno surdo seja alfabetizado em sua língua materna (Libras, no nosso contexto de pesquisa) uma vez que é através dessa língua de sinais brasileira que o aluno vem a ter acesso à modalidade escrita da língua portuguesa como L2, já que as línguas de sinais não

\footnotetext{
${ }^{1} \mathrm{Na}$ visão pós-moderna das ciências humanas o termo inclusão denota ser compromisso de todos e se distingue de integração cuja tarefa seria exclusiva de especialistas da educação especial, um serviço historicamente prestado por médicos, técnicos, otorrinos, fonoaudiólogos, psicólogos, psicopedagogos etc.

${ }^{2}$ L2 é o termo para se referir ao ensino de língua estrangeira no país no qual esta é falada como língua materna de minorias e/ou oficial-nacional. Entenda-se que a linguagem de Sinais Brasileira, LSB, ou ainda LIBRAS - Língua Brasileira de Sinais - é a L1, i.é., o meio legal, para o surdo brasileiro, de comunicação e expressão além de outros recursos a ela associados. Contudo ela não pode substituir a modalidade escrita da língua portuguesa, a qual constitui a L2 do surdo na educação inclusiva.
} 
possuem via de regra uma modalidade ${ }^{3}$ escrita. O ensino da articulação de fonemas e palavras da língua portuguesa, como em qualquer outra língua oral, parece constituir um esforço clínico de "normalização/reabilitação" da fala do surdo. Desse ângulo, tal esforço se constituiria num contra-senso cognitivo com o qual não temos convergência.

Isso posto, faz-se necessário ainda uma breve alusão ao movimento comunicacional contemporâneo como fluxo metodológico majoritário no campo do ensino de línguas da área de Lingüística Aplicada e sua possível interação com as abordagens reconhecíveis na tradição de educação de surdos.

O comunicativismo é um movimento que emana da abordagem comunicacional de ensino de línguas e pode perfeitamente buscar interagir com as abordagens de educação de surdos supra expostas desde que se explicitem os termos de comparação. Com as três primeiras, a convergência não se mostra razoável já que elas procuram a normalização do falar e do ouvir, o que se chama nos dias atuais de "normalização do corpo" (SKLIAR, 2005, p. 68). Essas ditas abordagens vêem o surdo como portador de uma deficiência e que este deve ter seu aparelho fonador normalizado com vistas a sua reabilitação na sociedade, desconsiderando assim que o surdo possui uma cultura e uma língua, logo uma identidade própria. No que se refere particularmente ao bilingüismo é possível se tentar uma interface com o ensino de língua desde que apenas a modalidade escrita da língua ensinada seja considerada e assim mesmo da perspectiva de ser uma L2, evitando-se dessa forma o etnocentrismo lingüístico, e valorizando, por outro lado, a identidade na diferença.

Skliar (1997) propõe o termo "ouvintismo" para referir-se aos meios ou mecanismos de colonização curricular, entendendo-se por essa expressão a subordinação do currículo escolar ao ensino da oralidade (e através da oralidade, grifo nosso) nas escolas públicas e privadas que atendem alunos surdos. Perceba-se que o termo não abrange apenas o ensino de línguas, mas o ensino de todas as demais disciplinas. Logo, o ouvintismo não é uma abordagem de ensino/aprendizagem e aquisição de línguas, e sim uma postura política curricular com viés totalitário baseada nos modelos da sociedade que ouve.

Nossa percepção, ao contrário, de que uma capacidade de comunicação em Português L2 escrito aprendida via Libras pode significar ganhos educacionais e psicológicos importantes nos impeliu neste estudo a examinar a realidade em fluxo de uma sala comum de educação inclusiva do ensino médio numa escola pública regular do Distrito Federal com o propósito de se reconhecer ali a abordagem deveras praticada e suas implicações.

Julgou-se que a análise de uma aula representativa da rotina escolar estabelecida observada ao vivo, com a variedade de todos os seus elementos constituidores e/ou coconstituidores anotados e gravados em áudio no limite de três aulas consecutivas observadas, atenderia adequadamente o objetivo de buscar evidências interpretadas que revelassem a abordagem ou habitus (largamente implícitos) de ensinar de uma professora de língua materna (LM ou L1) focalizando a modalidade escrita do Português.

\footnotetext{
${ }^{3}$ Segundo Widdowson (2005, p. 94), modalidade é a maneira pela qual o sistema lingüístico se realiza enquanto uso em atos de comunicação dividindo-se em escrita, na qual a interpretação é expressa produtivamente enquanto escrita ou receptivamente na leitura, e falada, expressa produtivamente na forma do dizer e receptivamente na forma do ouvir compreendedor.
} 


\section{Coleta de registros de onde saíram dados}

As informações que servem de base interpretativa para este estudo foram levantadas em uma aula de LM em uma classe de inclusão com alunos surdos e ouvintes de segundo ano do ensino médio de uma cidade do DF (Distrito Federal). A classe tem trinta e dois alunos brasileiros, sendo vinte e seis ouvintes, um destes é hiperativo ${ }^{4}$, e o outro é conhecedor de LIBRAS por ter uma prima surda na família, além de seis surdos profundos ${ }^{5}$ com idade entre dezessete e vinte e quatro anos. Desses, dois são estagiários do STJ (Superior Tribunal de Justiça) e o outro é funcionário de uma empresa prestadora de serviços do HRT (Hospital Regional de Taguatinga). É importante ressaltar ainda que dentre os alunos surdos dois foram oralizados.

A professora é falante nativa do português brasileiro. Ela mantém um histórico de bons resultados dos seus alunos ouvintes no PAS/UnB (Programa de Avaliação Seriada da Universidade Federal de Brasília) e nas avaliações escolares bimestrais. Ela também angariou um prêmio em concurso público de redação com alunos ouvintes sob sua orientação. A professora está prestes a se aposentar e é formada em Letras, mas não possui capacidade comunicativa em LIBRAS (Língua Brasileira de Sinais) também conhecida como LSB (Língua de Sinais Brasileira) que é a língua oficial dos surdos brasileiros reconhecida oficialmente pela Lei 10.436, de 24 de abril de 2002, e regulamentada pelo Decreto 5.626, de 22 de dezembro de 2005. Contudo, conta com a cooperação de um tradutor-intérprete educacional de sinais (um dos autores aqui), também licenciado em Letras e que concluía no momento da pesquisa um programa de mestrado em LA (Lingüística Aplicada) na UnB.

Os dados foram retirados dos registros de uma observação de aula de produção textual com duração de cinqüenta minutos. Os excertos foram extraídos de transcrições de fala interativa filmada numa turma de segundo ano do ensino médio da rede pública do DF. Justifica-se a opção pela filmagem, pois sem ela seria impossível a transcrição de LIBRAS neste trabalho. Foram utilizados dois métodos de transcrição distintos, a saber: (i) o de Felipe (2007, p. 24-27) para a transcrição de LIBRAS para a Língua Portuguesa; e o de Jefferson (2004, p. 14-31) para representar as interações de fala através da escrita.

A construção dos dados da investigação se deu através da filmagem da aula ministrada com posterior transcrição das falas em LIBRAS e em Português. Optou-se por tais procedimentos devido ao fato de se adequar melhor à transcrição de uma língua de sinais tanto quanto à transcrição de uma língua oral procurando-se, assim, a maior clareza entre os diálogos como também se evitar etnocentrismos lingüísticos em contexto de educação inclusiva. O intérprete de sinais que também é um dos articulistas por estar desempenhando sua função na ocasião da aula se encontrava impossibilitado de tomar notas de campo.

\footnotetext{
${ }^{4}$ Hiperatividade ou Desordem do Déficit de Atenção: estado geralmente caracterizado por problemas de aprendizado e comportamento tais como falta de atenção, impulsividade, instabilidade emocional.

${ }^{5}$ Segundo Vilhalva (2004, p. iii), considera-se como média clínica razoável para o melhor ouvido (avaliação para a chamada "zona da fala" ou "zona conversacional"):

Deficiência auditiva leve: perda entre 20 e $40 \mathrm{~dB}$;

Deficiência auditiva moderada: perda entre 40 e $60 \mathrm{~dB}$;

Deficiência auditiva severa: perda entre 60 e $80 \mathrm{~dB}$;

Deficiência auditiva profunda: perda acima de $80 \mathrm{~dB}$.
} 
A escola inclusiva na qual foi desenvolvido o levantamento de dados já foi premiada pela UNESCO devido a um projeto bem sucedido de orientação juvenil. Ela costuma aparecer em matérias jornalísticas na mídia devido a seus projetos inovadores e algumas vezes polêmicos.

A turma possui mapa de sala sendo a configuração da classe a seguinte:

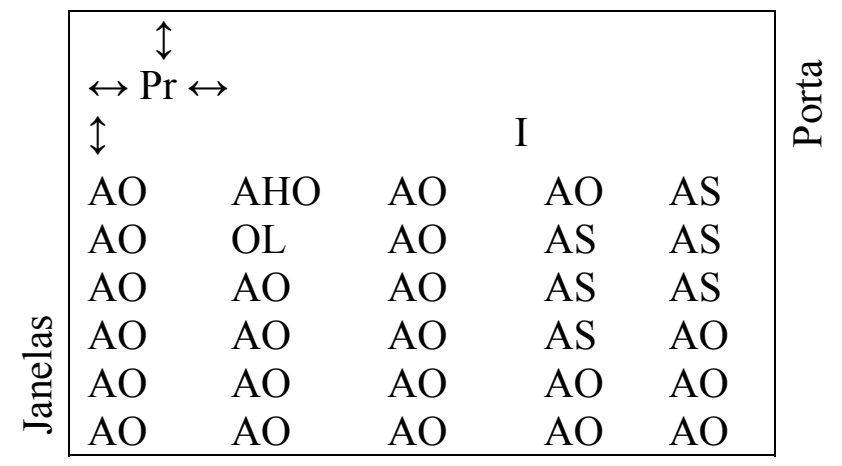

Quadro 1: Mapa de sala da turma inclusiva analisada.

\begin{tabular}{|l|l|}
\hline I & intérprete educacional de sinais \\
\hline AS & aluno surdo \\
\hline Pr & professor regente \\
\hline AHO & aluno hiperativo ouvinte \\
\hline AO & aluno ouvinte \\
\hline OL & $\begin{array}{l}\text { aluno ouvinte conhecedor de } \\
\text { LIBRAS }\end{array}$ \\
\hline$\uparrow \leftrightarrow$ & movimentação do professor regente \\
\hline
\end{tabular}

Tabela 1: Legenda

Neste tipo de classe o professor regente goza de ampla mobilidade, mas a mobilidade do intérprete de sinais é mais limitada devido à natureza de sua função. Contudo, isso não quer dizer que este não possa se deslocar quando a aula assim o exigir. O intérprete desempenha seu trabalho em pé e, rara vez sentado (devido ao cansaço de seis aulas consecutivas), ${ }^{6}$ sempre de frente para a classe. $\mathrm{Na}$ escola em questão os intérpretes permanecem em sala durante seis horas/aula por dia, cinco dias por semana, interpretando todas as disciplinas do currículo escolar. Assim, os professores trocam de turmas, mas os intérpretes não, sendo um intérprete por turma de inclusão.

Essa jornada somada às condições de trabalho têm implicações negativas para o desempenho do intérprete, pois ao se aproximar das últimas aulas o cansaço físico e mental comprometem a qualidade das interpretações e, consequentemente, a aprendizagem dos alunos surdos da classe.

\footnotetext{
${ }^{6} \mathrm{Um}$ intérprete no DF não possui as chamadas janelas, horário vago, que um professor regente costuma ter por não estar com sua carga de horas-aula completa.
} 


\section{Análise}

A professora começou explicando que a aula daquele dia teria como foco a produção de resumo de um texto denominado "INTERNET". Observou-se que a professora não adotava um livro didático para apoiar suas aulas e que seus materiais eram selecionados por ela mesma em fontes como a rede mundial e revistas. Nessa aula a professora não fez uso do retroprojetor, do projetor digital ou do quadro, embora tenha usado seu notebook para mostrar conteúdos da rede para a turma.

A professora pediu que algum aluno começasse a ler em voz alta. Uma aluna ouvinte, prontificando-se, começou a leitura enquanto era simultaneamente interpretada para os alunos surdos presentes na classe. O texto usado vai reproduzido a seguir:

\section{INTERNET}

A internet é a maior interligação de computadores do mundo e a responsável por uma mudança de comportamento de seus usuários. É também um fenômeno político e econômico.

Por permitir tudo, qualquer coisa, qualquer mensagem, séria, mentirosa ou absurda, torna-se democrática demais, israelenses e palestinos, pornógrafos, evangélicos, PT e PSDB, flamenguistas e vascaínos, punks e skin-heads, todos podem ter seu site.

Mas, não nos deixemos enganar, essa diversidade e democracia não é acessível (sic) a todos, ainda vivemos e um mundo desigual onde a maioria não pode adquirir um computador e ainda mais mantê-lo ligado à internet.

$\mathrm{O}$ grande mérito da internet está na democratização do conhecimento e no suporte da inteligência coletiva. Outra vantagem está no conforto, podemos, por exemplo, enviar uma mensagem para qualquer parte do planeta sem sair de casa, sem enfrentar trânsito, frio ou chuva para dirigirmos-nos a uma agência dos correios. Devemos reconhecer também os efeitos negativos que a internet tem acarretado na vida das pessoas, como o a dependência, há jogos em mundos virtuais que levam ao vício. Ocorre o isolamento e o estresse pela sobrecarga, além da bobagem coletiva, com fofocas e conformismos em rede ou em comunidades virtuais. Outra preocupação é que a internet tem servido, muitas vezes, ao poder dos grupos econômicos mais ricos, em prejuízo dos mais pobres que não conseguem alcançar o concorrente.

É de fundamental importância compreendermos que a radicalidade não nos permitirá uma visão clara da realidade de fato, com a realidade virtual. Precisamos saber usar esse ciberespaço de maneira racional e positiva para nossas vidas. ${ }^{7}$

Este primeiro procedimento pareceu impedir que os alunos surdos tentassem uma compreensão autônoma e eficiente do texto para leitura em Português e que, através da interpretação, ${ }^{8}$ chegassem à força e à significação ${ }^{9}$ de palavras e frases, conforme Widdowson (2005, p. 25-29).

\footnotetext{
${ }^{7}$ TEIXEIRA, Jerônimo. In: Superinteressante, São Paulo: Abril, ago. 2000. Texto adaptado pela professora da disciplina.

${ }^{8}$ Segundo Widdowson (1978, p. 102, 141), interpretar é assimilar sentidos, enquanto que discriminar é avaliar a significação relativa da informação.
} 


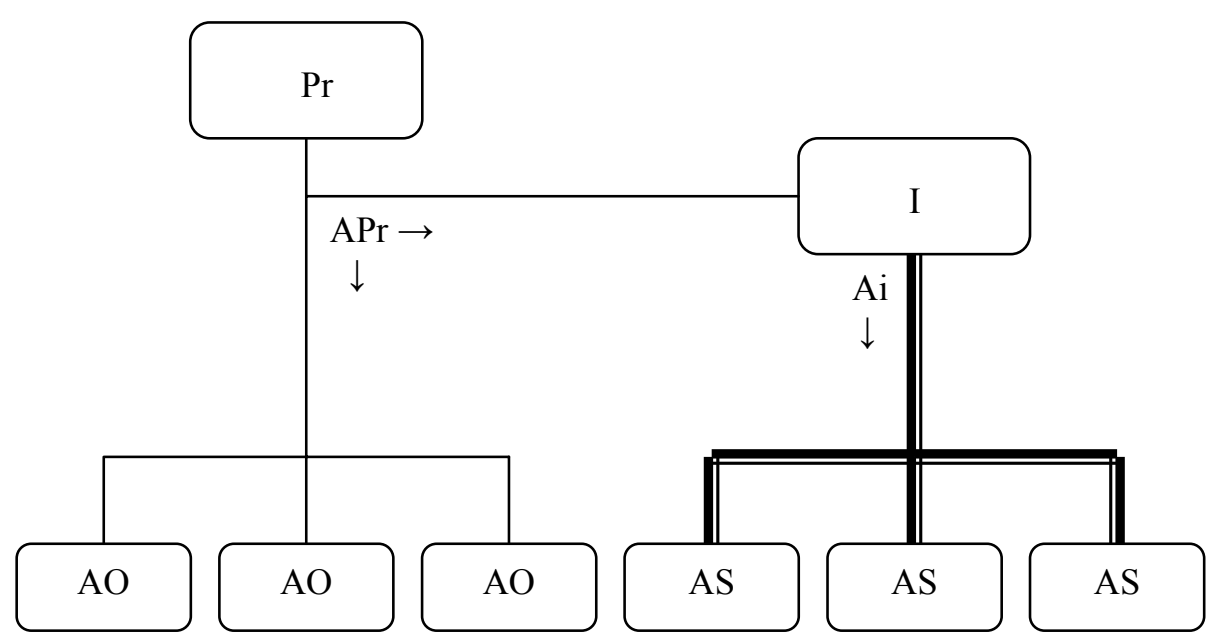

Gráfico 1: Processo de interpretação de aula.

\begin{tabular}{|l|l|}
\hline $\operatorname{Pr}$ & professor regente \\
\hline $\mathrm{APr}$ & aula do professor regente \\
\hline $\mathrm{I}$ & intérprete educacional de sinais \\
\hline $\mathrm{Ai}$ & aula interpretada \\
\hline $\mathrm{AO}$ & aluno ouvinte \\
\hline $\mathrm{AS}$ & aluno surdo \\
\hline \hline & $\begin{array}{l}\text { O entre-espaço branco se refere às perdas durante a } \\
\text { interpretação, a linha mais cheia representa uma equivalência } \\
\text { menor entre a aula e a aula interpretada, já a linha menos cheia } \\
\text { representa uma equivalência maior. }\end{array}$ \\
\hline
\end{tabular}

Tabela 2: Legenda

Observe-se (Gráfico 1) que o conteúdo da aula que chega aos alunos surdos é o mesmo que chega ao intérprete, contudo o conteúdo que chega aos alunos surdos já não é o mesmo proferido pelo professor. O que chega a estes alunos é uma re-expressão de uma língua na outra. Isso se deve ao fato de que mesmo o intérprete procurando realizar as equivalências da língua de partida (Língua Portuguesa) na língua de chegada (LIBRAS), não existe, devido às diferenças culturais, uma interpretação ipse litera, entenda-se forma a forma, mesmo em sala de aula, por melhor que seja a capacidade de compreensão e expressão do intérprete nas duas línguas.

Este parece ser o mesmo caso de interpretações em outras línguas também, porém neste contexto específico de interpretação voz/sinais ${ }^{10}$ em classe inclusiva de alunos surdos e ouvintes a questão se agrava como se verá logo nas primeiras transcrições abaixo, porque a classe não é de L2 para surdos usuários de LIBRAS e sim de LM com mediação de um intérprete educacional de sinais.

\footnotetext{
${ }^{9}$ Significação é o sentido expresso pela combinação de palavras dentro de estruturas regidas por regras gramaticais. Força é a significação assumida pela frase ou partes dela quando postos em uso para fins de comunicação.

${ }^{10}$ Nesta situação o professor fala e o intérprete traduz para a linguagem de sinais. O contrário (sinais/voz) seria o aluno surdo sinaliza e o intérprete traduz para a modalidade oral do português.
} 
Dois outros pontos observados durante a análise de abordagem foram o insumo, ${ }^{11}$ (KRASHEN, 1982, p. 9), na L-alvo (Língua Alvo) e o filtro sócio-afetivo, ${ }^{12}$ (DULAY; BURT, 1977). Isso se demonstrará nas transcrições mais adiante.

Uma vez que o conteúdo do texto em língua portuguesa chegava aos surdos através de um tradutor-intérprete de sinais, o que os alunos surdos recebiam na verdade não era insumo direto e compreensível, calibrado na L-alvo, mas uma re-expressão da L-alvo na LM do surdo, ou seja, em LIBRAS.

Após a leitura, o segundo procedimento da atividade da professora foi pedir aos alunos que revelassem oralmente a idéia central do texto. Sabe-se que o défice lingüístico-comunicativo de um aluno com surdez profunda é patente pela pouca prática de leitura e, paralelamente, pouco conhecimento de mundo. É possível se entrever, a partir das transcrições abaixo, que a aluna surda não alcançou captar a idéia principal do texto, enquanto seus colegas ouvintes demonstram justamente o contrário.

01 Profa. Ana ${ }^{13}$ : muito bem então (.) essa leitura ta? nos permite pelo menos reconhecer qual $\underline{\mathrm{e}}$ a idéia central desse texto (.) ta claro isso ai (.) num ta (.) pra todo mundo? quem e capaz de me dizer qual e a idéia central desse texto? ele fala de que?

02 Um grupo de alunos ouvintes: da [internete]

03 Profa Ana: da [internete] (.) e: que enfoque sobre a internete?

04 Cláudio, aluno ouvinte: o que $\underline{\text { e }}$ (.) e as características

05 Profa Ana: [o que é a internete e AS características da internet]

06 Maria: [2s LISTA INTERNETE $_{1 \mathrm{~s}}$ ]

(a aluna diz para o intérprete que o texto fala de uma lista da internete).

Convém lembrar neste ponto que os professores ainda não começaram a ser preparados em suas licenciaturas para o trabalho de compreensão leitora com alunos surdos.

O terceiro procedimento da professora foi pedir à classe que sublinhasse as idéias principais de cada parágrafo e aqui também se destaca uma dificuldade a mais. Como uma interpretação entre línguas não acontece palavra-por-palavra e como não se marcam porções de texto não-escrito na interpretação, os alunos surdos não encontravam a correspondência linear nos períodos do texto. Isso levou a professora a optar por sublinhar ela mesma, no texto de cada surdo, os períodos necessários ao resumo em vez de tentar o calibramento ${ }^{14}$ da linguagem do texto Krashen (1982).

Por último a professora pediu que todos montassem seu resumo a partir do agrupamento e organização das idéias principais grifadas em cada parágrafo, mas essa atividade não chegou a ser conferida por ela durante o restante da aula e é provável que

\footnotetext{
${ }^{11}$ Amostras de fala na L-alvo (para os fins deste trabalho amostras de língua escrita também) que contenham estruturas um pouco além do nível atual da competência do aprendiz e cuja compreensão é possível devido ao contexto e/ou informações extralingüísticas que podem levar à aquisição da L-alvo. Seria a variável causativa primária na aquisição de L2.

${ }^{12}$ Fatores sócio-afetivos relacionados ao processo de aquisição de L2 levam o aprendiz a buscar mais insumo compreensível ou a fossilizar a interlíngua.. Essa seria a variável causativa secundária.

${ }^{13}$ Todos os nomes adotados aqui são fictícios, Maria é o nome escolhido para se referir a única aluna surda que participa dos turnos de fala, apesar de haver mais quatro surdos naquela ocasião em sala.

${ }^{14}$ Amostras de fala (insumo ou output) que sendo calibradas (ajustadas) para o nível de competência lingüística do aprendiz se diz finamente calibrada, e sendo calibrada para diferentes níveis de competência do aprendiz (mais avançados e menos avançados) se diz grossamente calibrado. $\mathrm{O}$ insumo grossamente calibrado, com foco no uso, no contexto e nas informações extralingüísticas apresentaria vantagens sobre o insumo puramente calibrado, ou seja, com foco na forma e na gramática. (KRASHEN, 1982, p. 13)
} 
isso se traduza em perda lingüístico-comunicativa para os alunos surdos que têm nessas aulas sua única oportunidade de aprendizagem da língua portuguesa na modalidade escrita. Em seguida, a professora passa à exibição de conteúdos da internet através de seu notebook.

Num dado momento se percebe o interesse da professora em esclarecer dúvidas contextuais a respeito de alguma palavra do texto. Nesta primeira transcrição, essa atitude da professora parece ser suficiente para a compreensão de uma pequena passagem do texto, mas teria sido suficiente para desencadear a operação do DAL (ELLIS, 1997, p. 32), dispositivo de aquisição de linguagem ${ }^{15}$ ? A aluna surda seria capaz de fazer uso comunicativo, em contexto adequado, do termo abaixo num texto escrito? Voltaremos a esta questão mais adiante.

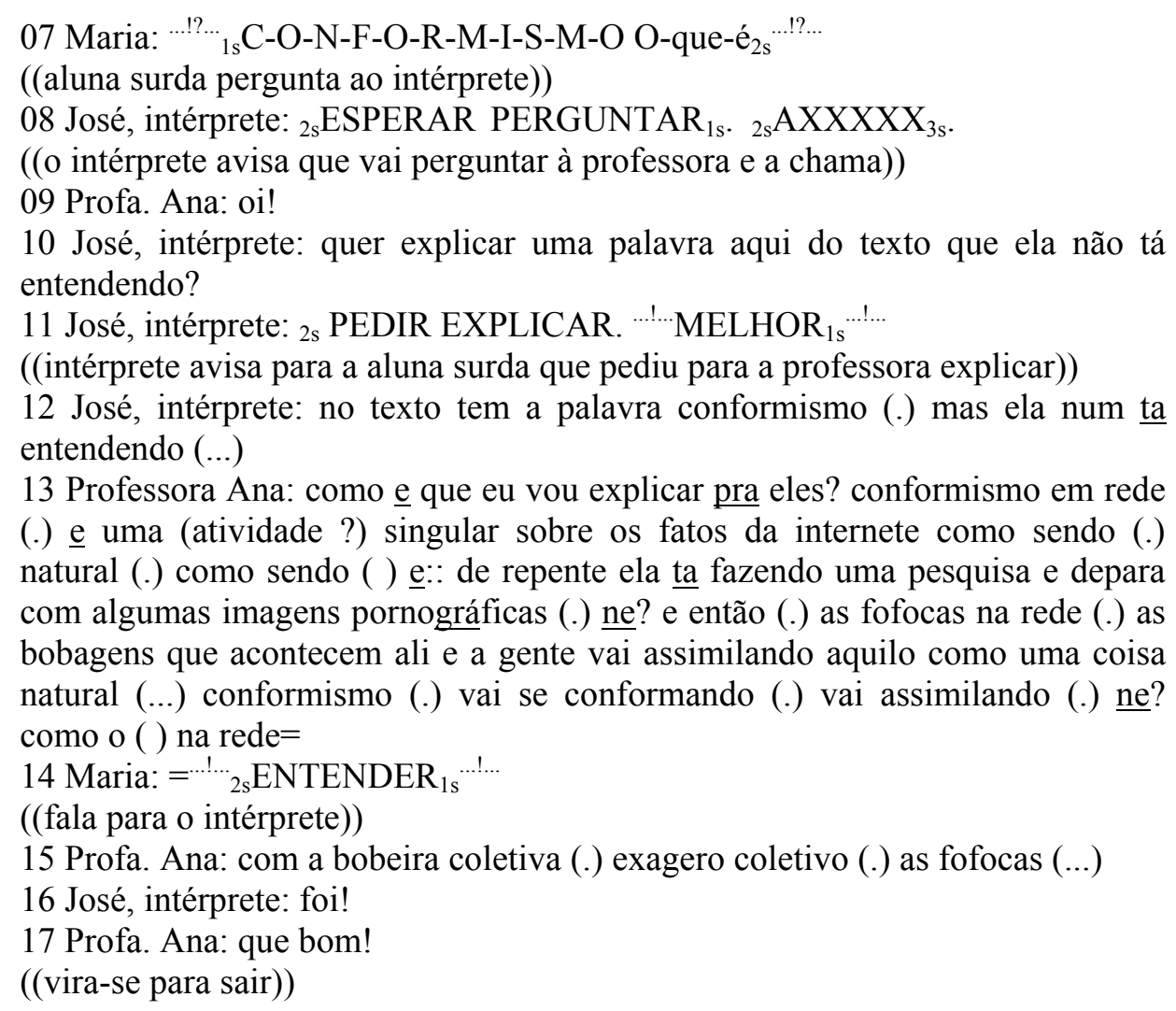

Nota-se aqui que o foco neste ponto recai em certificar se a aluna surda sabe ou não o que significa a palavra exposta acima, afinal dificuldades para se entender um determinado vocábulo todos temos em algum momento. Trata-se, então, de verificar se o insumo oferecido pela professora estava adequado ao ensino de português escrito como segunda língua para alunos surdos de modo a levá-los à compreensão do termo no contexto em que foi utilizado. Isso ocorre porque, a compreensão de um vocábulo desconhecido pelo estudante, seja de LM ou L2, depende também do insumo que lhe é apresentado. Em outras palavras, "o papel do insumo, segundo a teoria mentalista de aprendizagem de língua, é somente o de desencadear as operações do dispositivo de aquisição de linguagem" ou seja o DAL (ELLIS, 1997).

\footnotetext{
${ }^{15}$ DAL: dispositivo de aquisição de linguagem, faculdade inconsciente responsável pela fluência em uma L-alvo, sua contraparte seria o monitor, (KRASHEN, 1981, p. 16), o dispositivo responsável pela aprendizagem, portanto consciente, das regras, das normas, das estruturas, enfim da gramática de uma Lalvo.
} 
A professora deixa transparecer na transcrição (13) que tem dificuldade para explicar o termo para a aluna em questão, sendo esta uma situação muito comum entre professores que ensinam línguas nesse tipo de classe de inclusão. Embora a professora tenha explicado o que é conformismo ela não conseguiu ir, além disso, por exemplo, oferecendo exemplos, situações que reforçassem a explicação dela e calibrasse o insumo dado talvez porque ela crê-se que ensinar língua materna para o surdo não exija grandes diferenças metodológicas.

A esta altura, a professora apresenta em seu computador portátil, posto sobre uma cadeira em cima de sua mesa, um vídeo retirado da internete, legendado, mostrando alguns participantes desclassificados do reality show brasileiro Ídolos. Nele, alguns participantes cantam passagens do Hino Nacional de forma errada o que dá ao vídeo um tom de piada. O vídeo desperta risos na turma de ouvintes, contudo os alunos surdos não conseguem entender a hilaridade do material, pois as legendas além de representarem a oralidade dos participantes (com um tipo de transcrição não convencional), também passam muito rápidas:

Transcrição do Hino Nacional do Brasil interpretado por participantes do reality show brasileiro Ídolos e utilizada pela professora na aula.

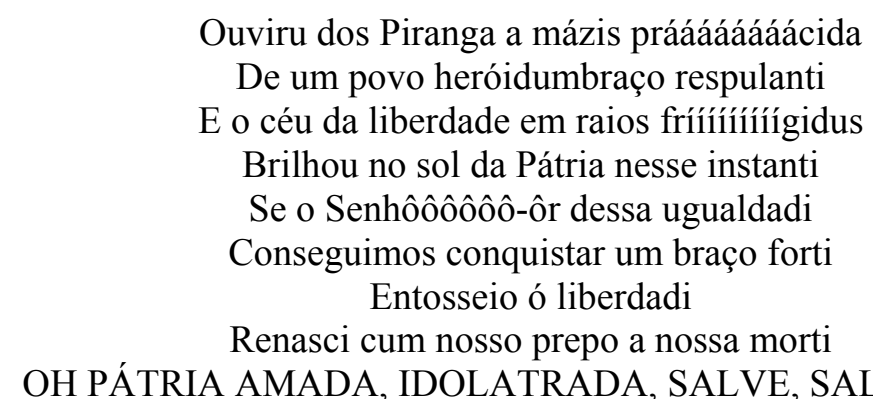

Ouviru dos Piranga a mázis práááááááácida

De um povo heróidumbraço respulanti

o céu da liberdade em raios fríííííííígidus

Brilhou no sol da Pátria nesse instanti

Se o Senhôôôôôo-ôr dessa ugualdadi

Entosseio ó liberdadi

OH PÁTRIA AMADA, IDOLATRADA, SALVE, SALLLLLVE!

Dos filhos desse sós e mais gentils...(?)

Pátria amada, Brasil! (sic) ${ }^{16}$

Isso remete mais uma vez às questões do insumo de qualidade e do devido calibre deste para alunos surdos. É necessário se ter em vista que alunos surdos não têm a mesma fluência de leitura e escrita que têm os seus colegas ouvintes da sala de inclusão, então, sem audição, o exercício de leitura das legendas acima, em velocidade de fala e cantada, se tornaria impossível, e todo o esforço dos alunos surdos resultaria em vão.

É razoável se considerar, a partir das transcrições abaixo, que o calibramento adequado a um aluno surdo pode ter nuances características diferindo, portanto, do calibramento que se faria para um aluno ouvinte.

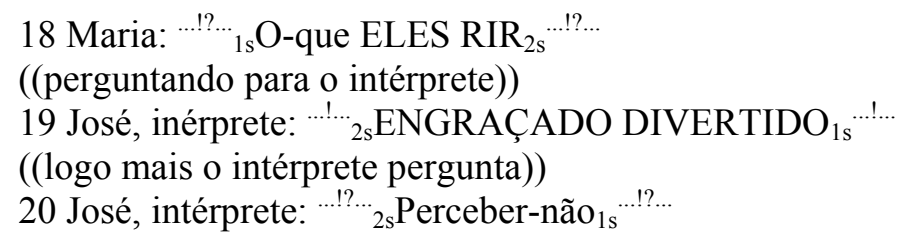

Numa mensagem eletrônica rotulada Céus! Estudar pra quê? a classe ria enquanto a professora lia em voz alta as malfadadas frases de jogadores brasileiros bemsucedidos no futebol, porém os surdos continuavam sem entender a graça dos textos

\footnotetext{
${ }^{16}$ Disponível em: $<$ http://www.youtube.com/watch?v=xiLB1kQeGik>.
} 
devido às peculiaridades lingüísticas das falas dos jogadores. A professora não consegue comunicar a chave para o riso aqui - o desajuste de quem ficou rico e famoso sem estudo e esmero cultural.

21 Profa. Ana: quando o jogo esta a mil minha NAFTALINA sobe (...) Jardel (.) ex-atacante do Vasco e Grêmio na Seleção > hoje na seleção de Portugal<

22 Maria: ${ }^{\cdots ! n ? \ldots}{ }_{1 s} \mathrm{O}$-que-é N-A-F-T-A-L-I-N-A ${ }_{2 s} \ldots ! ?$ ?...

23 José, intérprete: o que e naftalina ? para ela (...)

((indicando a aluna que fizera a pergunta))

24 Profa. Ana: e uma bolinha branquinha que eles colocam dentro dos armários para espantar insetos (.) baratas (.) ne!?

((vira-se para o laptop))

25 Maria: ${ }_{1 s} \mathrm{JÁ}_{\mathrm{VI}}$

Aparentemente, nessa passagem, a professora não percebeu que a aluna não conhecia as palavras naftalina e adrenalina, embora conhecesse o referente de naftalina e não conhecesse o referente de adrenalina. Como a aluna continuasse sem entender a troca que o jogador fez entre naftalina e adrenalina é razoável supor que a aluna não compreendesse também a relação força/significação neste contexto de uso comunicativo, Widdowson (1978, p. 34).

26 José, intérprete: ela não entendeu ainda (.) você̂ pode explicar?

27 Maria: ${ }^{\cdots ! \ldots}{ }_{15} \mathrm{DEIXA}_{2 \mathrm{~s}}{ }^{\ldots ! \ldots}$

A aluna surda responde para o intérprete dessa forma por provavelmente perceber certa impaciência na professora. Nesse momento, é visível o enrijecimento do filtro sócio-afetivo, está patente a desmotivação e a ansiedade da aluna impedindo tanto que ela compreenda a mensagem quanto que qualquer tipo de insumo seja processado no jogo de aquisição de língua, Dulay e Burt (1977, p 56). Ressalte-se que a recorrência do enrijecimento do filtro pode levar à fossilização ${ }^{17}$ de modalidades baixas de interlíngua.

28 Profa. Ana: ele [trocou adrenalina]

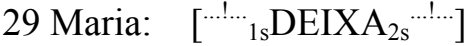

30 Profa. Ana: (.) né (.) quando você está diante de fortes emoções a adrenalina sobe (.) ? e ele disse que a naftalina subiu (.) ele trocou a adrenalina por naftalina

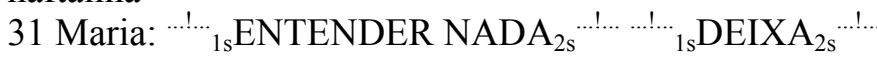

32 José, intérprete: ela não conseguiu entender ainda (...)

Nesse ponto, ouve-se o toque da campainha sentenciando o fim da aula da qual não parecia haver proveito para os alunos surdos. Embora não se tenha filmado as aulas subseqüentes, percebeu-se que nas próximas aulas não se voltou a este tópico. Ele foi considerado, portanto, matéria vencida e passando-se adiante não se concretizou a necessária interação ${ }^{18}$ de conceitos nos termos de Ausubel $(1978$, p. 54) que diz que "a

\footnotetext{
${ }^{17}$ São os erros e desvios no uso da língua estrangeira, internalizados e difíceis de serem eliminados levando à interrupção do fluxo normal de desenvolvimento da fala. É característica de quem estuda línguas, especialmente na infância, sem ter contato com falantes nativos.

${ }^{18}$ Diferentemente da hipótese da interação de Schumann (1978b) para a qual a aquisição da L-alvo é controlada pela integração social e contatos do aprendiz, ou seja, é controlada pela aculturação.
} 
noção de interação significa a ação recíproca entre um conhecimento específico, préexistente, subsunçor (do inglês subsumer), com um novo conhecimento".

\section{Concluindo}

Apesar de ser uma classe de inclusão de aprendizes surdos ao meio de linguagem para ouvintes, evidenciou-se uma cultura de ensinar LM fortemente centrada na oralidade com grande quantidade de insumo oral e uma escassez de linguagem de qualidade e adequada para a minoria de alunos surdos presentes na sala tida oficialmente como de inclusão. Observou-se que não existe na aula o que poderia se chamar de insumo escrito uma vez que em práticas como a de resumo em nossa situação de pesquisa não se concretizaram em nenhum momento. Isso parece ser relevante para todos os alunos, mas principalmente para os aprendizes surdos que têm na modalidade escrita da língua portuguesa a sua L2 de comunicação na sala. Em razão disso, não foi possível, por exemplo, responder à questão do uso da palavra "conformismo" no andamento das interações realizadas em sala de aula.

Como decorrência do excesso de insumo oral, nem as explicações do intérprete oficial presente na sala pareceram esclarecedoras aos alunos surdos. No que tange os materiais selecionados pela professora (mensagens eletrônicas e excerto de vídeo retirados da internet), embora esses parecessem contextualizados na aula produzida, e ainda que sua articulação tenha sido discutida com a turma, eles não se adequavam, ou antes, a abordagem da professora não conseguia adequá-los, às condições lingüísticocomunicativas dos alunos surdos.

Devido ao estilo oralista de se ensinar LM aos surdos, os filtros afetivos dos alunos não-ouvintes tiveram chances reais de se elevarem impedindo-os de se sentirem motivados para a aprendizagem da língua portuguesa escrita (como L2) e da compreensão de leitura, o que se traduziu em desistência de compreensão e possível bloqueio do que Widdowson $(2005$, p. 91 e 217) chama de capacidade interpretativa subjacente.

O ensino de língua, portanto, não ajudou na aquisição do Português Escrito L2 pelos alunos surdos, pelo menos não nas interações observadas nesta pesquisa, já que não se constituiu um contexto de abundante uso da língua/modalidade-alvo sob baixa pressão do filtro e ampla compreensibilidade dos insumos trazidos e dos co-construídos em sala.

A sala de aula inclusiva parece resultar de uma atitude afirmativa e positiva. Contudo, nossos resultados neste estudo parecem confirmar que alunos surdos e ouvintes agem dentro do que Almeida Filho (2007, p. 13) chama de culturas de aprender ${ }^{19}$ distintas, necessidades lingüístico-comunicativas sui generis, além do que se pode chamar de interlíngua com forte dependência da escrita, no caso do aluno surdo.

Já que uma professora não poderá ter duas abordagens simultâneas em sala de aula, uma para alunos ouvintes e outra para surdos, parece razoável no que concerne o ensino de L2 para surdos que estes tenham uma sala especialmente designada para eles, assim como materiais e professores formados ou ao menos sensibilizados para o ensino específico da LP escrita como L2.

\footnotetext{
${ }^{19}$ Maneiras de aprender típicas da região, etnia, classe social e até do grupo familiar, restritas do aprendiz em alguns casos. Evoluem no tempo em forma de tradições e normalmente informam a maneira naturalizada, subconsciente e implícita de aprender uma L-alvo.
} 
Se essa transformação da prática não se efetuar, vamos seguir prestando homenagem a um discurso inclusivista que não se sustenta na prática por resultados compensadores traduzidos por uma cada vez maior capacidade de usar o PL2 escrito por parte de minorias surdas para se educar de maneira integrada nas escolas. Precisamos neste caso produzir uma consciência do que de fato ocorre nesses contextos ditos inclusivos, ou o que Prabhu (1990, p. 172) chama de "senso de plausibilidade"20 para o ensino de uma L2. Da mesma forma os aprendizes, ouvintes ou surdos, indistintamente, devem ter a oportunidade de refletir sobre essa situação via reflexão coordenada pelo professor a princípio. Com essa compreensão acerca do próprio ensinar e do próprio aprender, os currículos devem buscar um sentido geral de satisfação e coerência sobre o que é ensinar uma L2 para alunos surdos, em que modalidade ensiná-lo, e ainda pensar no que educação transformada trará de fato em termos de mais valia para suas vidas. A aula de L2 renovada poderia encontrar subsídios importantes numa filosofia comunicacional sensível às características do surdo que buscasse o melhor aproveitamento e geração de insumo específico para esse público e desenrijecimento do filtro do aluno surdo, prevenindo o engessamento da interlíngua escrita e permitindo a inclusão bem sucedida dos alunos surdos na escola e na sociedade exterior operada majoritariamente em Português neste país.

\section{NOTAS}

01. Os autores agradecem à profa. Dra. Audrei Gesser, da Universidade Estadual do Norte do Paraná-UENP, pela leitura e comentários de uma versão preliminar deste texto. É claro que o conteúdo desta publicação, seus acertos e equívocos, permanecem sob nossa inteira responsabilidade.

02. As convenções utilizadas para a transcrição de LIBRAS para o português foram parcialmente baseadas em Felipe (2007):

\begin{tabular}{|c|c|}
\hline A-B-C-D & palavra dactilografada (dactilologia) \\
\hline A-bcd & duzido por duas ou mais palavras da LP \\
\hline $\mathrm{ABCD}$ & sinal traduzido por uma única palavra da LP \\
\hline $\begin{array}{l}1 \mathrm{~s}, 2 \mathrm{~s}, 3 \mathrm{~s} \\
\ldots \ldots \ldots . .\end{array}$ & $\begin{array}{l}1^{\mathrm{a}}, 2^{\mathrm{a}} \text { e } 3^{\mathrm{a}} \text { pessoa do singular } \\
\text { expressão facial e/ou corporal } \mathrm{p}\end{array}$ \\
\hline
\end{tabular}

03. As convenções utilizadas para a transcrição da fala do português foram parcialmente baseadas em Gail Jefferson (2004):

$\begin{array}{ll}? & \text { entonação ascendente } \\ ! & \text { entonação descendente } \\ (\text { ) } & \text { incompreensível } \\ ((\mathrm{XX})) & \text { comentário do transcritor } \\ {[\mathrm{XX}]} & \text { falas sobrepostas } \\ = & \text { fala colada } \\ : . & \text { alongamento da vogal } \\ (.) & \text { pausa breve } \\ (\ldots) & \text { pausa longa } \\ (?) & \text { palavra provável }\end{array}$

\footnotetext{
${ }^{20} \mathrm{~A}$ compreensão subjetiva do professor acerca do seu próprio ensino, o sentido interno de coerência nas explicações do que fazem ao ensinar. Este sentido é decorrente da Abordagem de ensinar do professor seja ela implícita ou explícita e é mais básico que a escolha do método.
} 


$\begin{array}{ll}\text { AXXXX } & \text { nome próprio } \\ \text { AAAAA } & \text { ênfase na palavra } \\ \underline{X X} & \text { sílaba acentuada } \\ { }^{\circ} \mathrm{XXX}^{\circ} & \text { fala com volume baixo } \\ >< & \text { fala mais rápida }\end{array}$

\section{Referências}

ALMEIDA FILHO, José Carlos P. Dimensões comunicativas no ensino de línguas. 4. ed. Campinas: Pontes, 2007.

AUSUBEL, David. Psicologia educacional. Tradução de Eva Nick. Rio de Janeiro: Ed. Interamericana, 1980.

BOURDIEU, Pierre Language and symbolic power. Cambridge: Polity Press, 1991.

DULAY, Heidi; BURT, Marina. Remarks on creativity in language acquisition. In: BURT, Marina; DULAY, Heidi; FINOCCHIARO, Mary. (Eds.). Viewpoints on English as a second language. New York: Regents, 1977.

ELLIS, Rod. Second language acquisition. Oxford: Oxford University Press, 1997.

FELIPE, Tanya A. Libras em contexto: curso básico. 8. ed. Rio de Janeiro, MEC, 2007.

JEFFERSON, Gail. Glossary of transcript symbols with an introduction. In: LERNER, Gene H. (Ed.). Conversation analysis: studies from the first generation. Amsterdam: John Benjamins, 2007.

KRASHEN, Stephen D. Principles and practice in second language acquisition. Oxford: Pergamon Press, 1982.

MARCUSCHI, Luiz Antônio. Análise da conversação. São Paulo: Ática, 1986.

PRABHU, Nagore S. There is no best method - why? Tesol Quartely, v. 24, n. 2, verão, 1990.

SCHUMANN, John. The acculturation model for second language acquisition. In: GINGRAS, Rosario. (Ed.). Second language acquisition and foreign language teaching. Arlington, VA: Center for Applied Linguistics, $1978 \mathrm{~b}$.

SKLIAR, Carlos B. A reestruturação e as políticas educacionais para as diferenças: o caso dos surdos. In: SILVA, Luiz Heron e AZEVEDO, José Clovis. (Orgs.). Identidade social e a construção do conhecimento. 1. ed. Porto Alegre: Ed. Mediação, 1997.

WIDDOWSON, Henry G. O ensino de línguas para a comunicação. Tradução de José Carlos Paes de Almeida Filho. 2. ed. Campinas: Pontes Editores, 2005.

\section{Webgrafia}


COUTO, Hildo Honório do. Línguas crioulas. Disponível em: $<$ http: \www.comciencia.br/reportagens/linguagem/ling11.htm>. Acesso em: 7 jun. 2007.

JEFFERSON, Gail. Basic transcription notation conventions. Disponível em: $<$ http://www-staff.lboro.ac.uk/ ssca1/notation.htm>. Acesso em: 7 jun. 2007.

LACERDA, Cristina B. F. de. A short history of different approaches to the education of the deaf. Cad. CEDES, Campinas, v. 19, n. 46, 1998. Disponível em: $<$ http://www.scielo.br/scielo.php?script $=$ sci_arttext\&pid=S0101$3262199800300007 \& \operatorname{lng}=$ en\&nrm=iso>. Acesso em: 1 jul. 2007. Pré-publicação.

SCHÜTZ, Ricardo. Interferência, interlíngua e fossilização. Disponível em: $<$ http: \www.sk.com.br/skinterfoss.htm>. Acesso em: 7 jun. 2007.

VILHALVA, Shirley. Despertar do silêncio. Editora Arara Azul. Coleção cultura e diversidade, 2004. Apoio IBM. Disponível em: <http:||www.editora-araraazul.com.br/pdf/livro1.pdf>. Acesso em: 7 jun. 2007. 